\title{
The Book Reviewing Adequacy of Certain Periodicals Relating to Higher Education
}

Now librarian of the Laboratory Schools of the Mansfield, Pa., State Teachers' College, Miss Steele received her master's degree at the School of Library Service, Columbia University, in 1940. The paper following is an abbreviated form of her master's essay and illustrates the second of the groups dealt with by Miss Fay on pages 207-16.

College librarians cannot depend $\mathcal{G}$ upon professional library literature alone for building up their book collections. The faculties of colleges and universities play an important role in the selection of books for the college library and they often depend upon reviews in their professional journals to aid in that selection.

The legitimacy of evaluating reviews for the purpose of library book selectionfor which purpose they were obviously not primarily written-may be questioned. However, since college professors and librarians do use such reviews for that purpose, it would seem worth while to examine them from the librarian's point of view, in an effort to discover their strength or weakness when used for book selection purposes in a college library.

The Problem. The purpose of this study is to discover whether professional journals in the field of higher education are adequate and sufficiently critical to be used for selection purposes.

\section{Procedures and Techniques}

Selecting the Journals. In selecting the journals to be examined, three separate lists were used. First, the classified list of educational publications issued each year by the Educational Press Association, ${ }^{1}$ yielded the following titles:

Higher Education

American Association of University Professors' Bulletin

Journal of Higher Education

Junior College Journal

Journals of Institutions for the Education of Teachers

Harvard Educational Review

Teachers College Record

Educational Research

Educational Research Bulletin

(Ohio)

Journal of Educational Research

The seven chosen titles were then compared with those in the Lyle list ${ }^{2}$ which included the following four: American Association of University Professors' Bulletin; Journal of Educational Research;

1 Educational Press Association. Fourteenth Yearbook, 1938 .

Pyle, G. R and Trumper, V. M. Classified List of Periodicals for the College Library. Faxon, 1938. 
Journal of Higher Education; and Teachers College Record.

In 1934 the North Central Association published a list which was prepared for their Committee on Revision of Standards for Institutions of Higher Education by the library subcommittee, with Douglas Waples as chairman. This list was checked by groups of carefully selected instructors, and one of the results is a list of periodicals ranked according to the purposes for which they are primarily used.

Comparing the seven titles taken from the Educational Press Association's Yearbook with the North Central Association's list, reveals which periodicals are most frequently read for professional purposes and which for research purposes. Their ranking is as follows:

\section{Instances of Uses of Journals}

$\begin{array}{lcc}\text { Name of Journal } & \begin{array}{c}\text { Professional Research } \\ \text { Purposes }\end{array} \\ \begin{array}{l}\text { Peachers College } \\ \text { Record }\end{array} & 32 & 18 \\ \begin{array}{l}\text { Journal of Educational } \\ \text { Research }\end{array} & 28 & 32 \\ \begin{array}{l}\text { Educational Research } \\ \text { Bulletin. }\end{array} & & \\ \begin{array}{l}\text { Journal of Higher } \\ \text { Education }\end{array} & 27 & 26 \\ \begin{array}{l}\text { Junior College } \\ \text { Journal }\end{array} & 24 & 7 \\ \quad\end{array}$

The American Association of University Professors' Bulletin and the Harvard Educational Review were not included in the North Central Association's list. However, since the bulletin of the A.A.U.P. is a professional journal which is included with membership in the association, it is assumed that many individual professors receive copies of it privately and it was therefore thought worthy of inclusion in the list of periodicals chosen for this investigation.

The Harvard Educational Review had not yet appeared when the North Central Association's list was made, but a journal published by the graduate school of education of one of our largest universities was thought worthy of inclusion for this study, particularly since it has a comparatively lengthy reviewing section.

The Educational Research Bulletin, published by the Bureau of Educational Research of Ohio State University, was dropped since it ranked slightly lower on the North Central list than the Journal of Educational Research, and one research journal seemed all that time would permit to represent that field in this study.

The list of periodicals used in this study finally included: American Association of University Professors' Bulletin; Harvard Educational Review; Journal of Educational Research; Journal of Higher Education; Junior College Journal; and Teachers College Record. The total number of reviews examined was 285 in the six journals mentioned above, the complete file for the year 1939 .

Determining the Criteria. The most difficult part of this study was to determine some objective method, if possible, for measuring the adequacy of a review. Because of the similarity of purpose, the field of textbook analysis was used as a basis in developing a score card to use in evaluating book reviews. While the criteria used for textbook evaluation have been severely criticized, they do "present a convenient means for checking different elements that must be considered if a textbook is fully to realize its purpose."3

Eleven different rating devices for textbooks were studied. They seemed to fall into two groups: rating scales and checklists. Since each rating scale used its own

\footnotetext{
${ }^{3}$ Maxwell, C. R. "Use of Score Cards in Evaluating Textbooks." In National Society for the Study of Education. Thirtieth Yearbook, pt. II, p. I49.)
} 
system of weights and since there seemed to be no agreement as to what the weight should be, it was thought that a checklist would give a more objective measure. It would note whether a characteristic were present or absent and would give a total of favorable or unfavorable items which could be compared with similar totals.

In developing this score card, all the items of information desirable in a review for book selection purposes were grouped and classified. The result was a list which could be checked with each book review. This preliminary checklist was sent to five librarians to obtain their judgment as to the items included and to several educators in the field of educational research to be passed on as to its correctness of form. It was then revised in the light of their criticisms and suggestions.

The score card of course had to be adaptable to different types of material. For example, fiction or literary works would call for different elements to be considered.

It is realized that reading a review and checking whether an element is present or not does not answer the question in terms of the extent to which that characteristic is present. That would depend upon the interpretation of the person using the score card. It was felt, however, that merely checking the absence or presence of characteristics would produce a score concerning the completeness of detail rather than the depth of treatment. Nor does this checking necessarily present a true picture of the book review. Much depends upon the authority of the reviewer of the book.

The score card used in checking the reviews was as follows:

\section{Score Card for Evaluating Reviews in Professional Education Periodicals}

\section{Authority of Reviewer}

Check

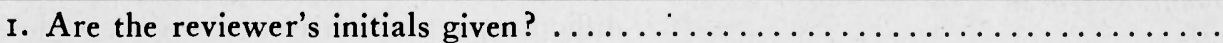

2. Is the full name of the reviewer given?

3. Is the full name plus a slight identification given?

4. Is the full name plus an incomplete reference given to his position or special field of work?

5. Is the full name plus a complete reference given to his position or special field of work?

(Note: Check each question in Section I rather than just the particular question that fits the case. Obviously if the full name and a complete reference to position are given, the other four questions have been covered.)

(Total-5)

TOTAL ..........

II. Manner and Treatment of the Review

Check

I. Does the reviewer attempt to give an impartial estimate of the book by:

Agreeing with the author's point of view?

Disagreeing with the author's point of view?

Holding the author to be in error or incomplete in his treatment of certain ideas?

(Note: Check only one of the above statements)

Does the reviewer compare the book to:

2. Other books in the same field or of a similar character? 
3. Theories or ideas of another author?

4. Does the reviewer give a concrete statement of his judgment of the bookwhether it is a good book, an outstanding book, good in spots, poor, or some such general appraisal?

5. Does he state whether or not it presents new material, new organization, new point of view, or new references?

6. Does the review appear within the year in which the book was published?...

(Total-6)

TOTAL $\ldots \ldots \ldots$

III. Comprehensiveness

Check

A. Scope and form of the book reviewed

Does the review answer the following questions?

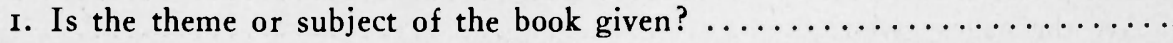

2. Is the scope of the book revealed?

(Does it cover the subject completely or partially; is it a history, survey, or discussion of certain aspects or conditions?)

3. Is the book brief, exhaustive, or selective?

4. Does it present theory or practice, facts or argument?

5. Is it a manual, textbook, report, yearbook, reference work, or monograph?

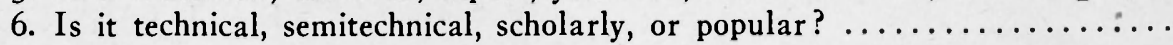

7. Does it give the author's purpose in writing the book?

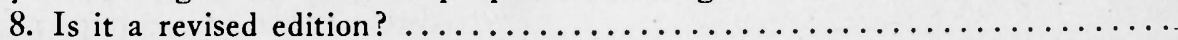

9. If so, does it describe the extent of the revision?

(Total-7 or 9)

A-TOTAL..........

B. Authority of the author of the book

I. Does the reyiew give the author's qualifications?

(His education, experience, or special preparation for writing the book)

2. Does it state the basis or sources of the book?

3. Does it state the quality of the sources?

(Total-3)

B-TOTAL.........

C. Manner and quality of treatment of the book reviewed

Does the review answer whether or not:

I. The author is biased?

(Does the review show whether he is a conservative, radical, or the exponent

of some particular school of thought?)

Does the review state whether or not:

2. The work shows any degree of originality or creative power?

3. It has a clear graphic style, charm, or imagination?

4. It has the quality necessary to make it a permanent contribution?

5. It shows balance (that is, the extent to which the author has put first things first)?

6. The book has value in its field?

(Total-6)

C-TOTAL.......... 
D. Physical features

Does the review state whether or not:

1. There is an index?

2. There are illustrations, maps, charts, documentation, etc?

3. There are bibliographies, appendices, or any other reference features?.

4. The book has a pleasing format?

(Total-4)

D-TOTAL..........

\section{E. Trade information}

I. Is the author entry given correctly?

2. Is the title given?

3. Is it given in full?

4. Are the pages given?

5. Is the date given?

6. Is it the copyright date?

7. Is the publisher given?

8 . Is the price given?

(Total-8)

E-TOTAL.........

IV-TOTAL.....

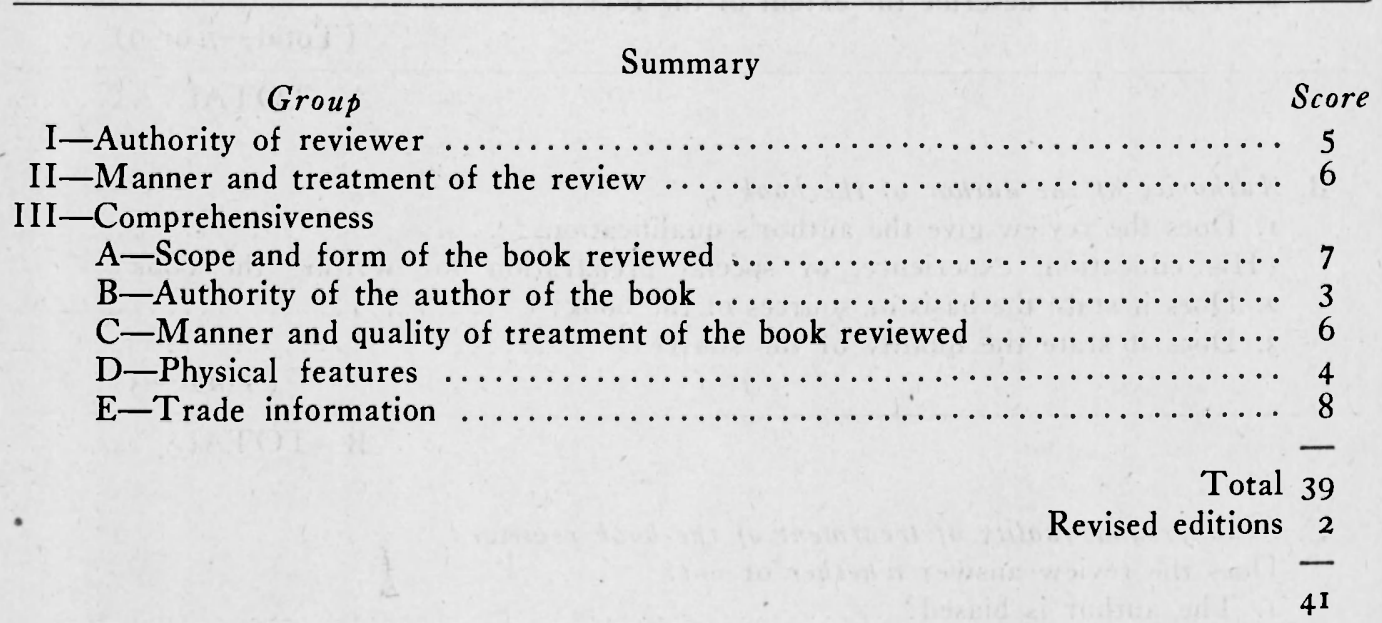

\section{Interpretation of the Findings}

The above score card will need to be consulted by the reader for identification of the points and categories here reported upon. On the first section of the score card-the authority of the reviewer-the Junior College Journal and the Teachers College Record made no scores since their reviews were not signed. It should be noted that the Teachers College Record reviews only monographs or Ph.D theses. Their reviews are mainly descriptive, giving the content and experimental method followed in each case but giving little information as to whether the monograph would be of value except as a piece of re- 
search. Consequently their ratings on this score card are quite different from those of the journals reviewing all types of published materials.

The Harvard Educational Review and the Journal of Educational Research rated highest on the authority of the reviewers. All the reviews in the latter gave the reviewer's full name and at least some reference to his position or special field of work, whereas about half of the reviews in the Harvard Educational Review did the same.

On the whole the Harvard Educational Review and the Bulletin of the American Association of University Professors rated highest in the manner and treatment of the review. The reviewers in about 8 per cent of the cases in both journals gave some general appraisal of the book (see score card, section II, 4). The findings on this section of the score card are given in full in the following table. haustive, or selective in their treatment.

Only twenty-one of the books were revised editions. The Junior College Jour$n a l$, with ten revised editions, described the extent of revision in seven cases. The Journal of Higher Education included two revised editions and in both cases gave something concerning the extent of revision, while the Harvard Educational Review included four revisions but fully described only one. Three out of five revised editions reviewed in the Journal of Educational Research were fully described. It would seem from this that one of the weakest points in the reviewing of education material is in the field of revised editions.

As to the authority of the author of the book, it is interesting to note that outside of the Teachers College Record which, as was mentioned before, is in a class by itself, the Bulletin of the American Association of University Professors and the

TABLE I

Manner and Treatment of the Review
A.A.U.P.
H.E.R.
I.E.R.
I.H.E.
I.C. I.
T.C.R."

Total number of reviews for each

Per cent of total number of reviews for each score

I. Impartial estimate $\ldots \ldots 7 \mathbf{7 2 . 2}$

84.4
14
15
80
68.8
88.8

$\begin{array}{lr}70.2 & 67.2 \\ 22.1 & 20.8 \\ 16.9 & 6.9 \\ 61 & 75.8 \\ 55.9 & 72.5 \\ 74 & 79.3\end{array}$

9.5
1.6
6.3
25.3
49.2
96.8

4. General appraisals ..... 77.7

5. New material ......... 83.3

6. Year of publication ...... I00

As to the scope and form of the book reviewed (see score card, section III, A) all reviews rated high on the first two points, the theme and scope of the book reviewed, but less attention was paid to stating whether the books were brief, ex-
Journal of Higher Education rated highest in describing the authorship of the books

\footnotetext{
4 Abbreviations used in these tables: A.A.U.P.Bulletin of the American Association of University Professors; H.E.R.-Harvard Educational Review; T.E.R.-Journal of Educational Research; J.H.E.Journal of Higher Education; J.C.J.-Junior College Journal; T.C.R.-Teachers College Record.
} 
they reviewed. Of course to professors and specialists in the field, the author's name itself will often carry with it all the necessary information.

The following table attempts to show evaluative criticisms that are important in helping the reader determine the merit of the book reviewed. The personal judgment of the scorer makes this section of the score card less objective than some others.
Higher Education, and the Junior College Journal gave more information in this section than did the other journals. Bibliographies, charts, documentation, and other reference features are important points to consider in selecting books for a college library, and it is to be regretted that mention of the presence or absence of such features is often neglected in book reviews as is shown by Table III.

In the main, the trade information

TABLE II

Manner and Quality of Treatment of the Book Reviewed reviews for each

Per cent of total number of reviews for each score

I. Bias $\ldots \ldots \ldots \ldots \ldots \ldots$. 50

2. Originality $\ldots \ldots \ldots \ldots \ldots \ldots+\mathbf{2 2 . 2}$

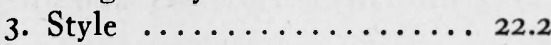

4. Contribution $\ldots \ldots \ldots \ldots \ldots$ 27.2

5. Balance $\ldots \ldots \ldots \ldots \ldots$ II.I

6. Value ............. 88.8 18
Total number of

A.A.U.P.

Table III gives the sort of information research workers and librarians are particularly interested in. The Journal of Educational Research, the Journal of
H.E.R. 45

$\begin{array}{cc}27 & 36.4 \\ 20 & 19.5 \\ 20 & 25.8 \\ 32 & 10.4 \\ 7 & 14.3 \\ 82.1 & 76.6\end{array}$

J.H.E. 58 J.C.J. 63
Total number of reviews for each

Per cent of total number of reviews for each score

1. Indexing $\ldots \ldots \ldots \ldots \ldots$ I I.I

2. Documentation $\ldots \ldots \ldots \ldots .27 .7$

3. Bibliographies ....... 22.2

4. Format

18 given was such that titles were easily verified, and so a table giving those results is not shown here.

From the examination of the above
TABLE III

Physical Features

A.A.U.P. H.E.R. J.E.R. J.H.E. J.C.J. T.C.R.

45

77

58

63

22

$\begin{array}{rr}29.3 & 6.3 \\ 13.8 & \\ 39.7 & 6.3 \\ 29.1 & 4.7 \\ 10.3 & 4.7 \\ 94.8 & 76.1\end{array}$


tables, it will be seen that on the whole the reviews rated high in presenting factual information but fell short on the criteria which would help to compare the book with other books in the same field; in other words, in helping to show whether the book is worth purchasing.

Of the 283 reviews rated on the score card, eighty were of books reviewed in more than one journal. Out of the total of 137 reviewers, only twenty-nine had more than one review to his or her name.

Length of the Review. Usually the longer the review, the higher it rated on the score card, although this was not true in several cases where the reviewer seemed to welcome the chance to express his own theories of education. The Journal of Higher Education and the Bulletin of the American Association of University Professors made the highest single scores, thirty-two out of possible thirty-nine points.

The following table shows the high, low, and median ratings the various journals made on their reviews as well as the total number of reviews each published during the year. ticularly how they choose their reviewers and the books to be reviewed and whether any definite instructions are given on how to write the reviews.

All the questionnaires were returned with the exception of that of the Teachers College Record, whose editor answered that they publish no book reviews as such. Their policy on book reviews is part of a more general policy of publishing only manuscripts submitted by staff members or graduate students working under their direction. The only material of the nature of a book review is in the section entitled "New Studies in Education," which comprises digests of the dissertations of Teachers College doctoral candidates.

The Harvard Education Review, the Journal of Educational Research, and the Journal of Higher Education in selecting their reviewers choose specialists not necessarily connected with their respective journals. The Junior College Journal uses members of its editorial staff for this purpose, and the American Association of University Professors usually chooses members of the association whose names

TABLE IV

Summary of Rating Scores

\begin{tabular}{|c|c|c|c|c|c|}
\hline Name of Periodical & High & Low & Median & $\begin{array}{l}\text { Number } \\
\text { of Reviews }\end{array}$ & $\begin{array}{l}\text { Number } \\
\text { of Issues }\end{array}$ \\
\hline$\ldots \ldots \ldots \ldots$ & 28 & 14 & 24 & 46 & 4 \\
\hline A.A.U.P. $\quad \ldots \ldots \ldots \ldots \ldots$ & 32 & 17 & 24 & 18 & 7 \\
\hline J.E.R. . NWW W W W & 30 & I 7 & 23 & 77 & 9 \\
\hline J.H.E. ….......... & 32 & 18 & 23 & 58 & 9 \\
\hline J.C.J. $\ldots \ldots \ldots \ldots \ldots$ & 23 & I0 & 16 & 64 & 8 \\
\hline T.C.R. & 17 & I2 & 15 & 22 & 8 \\
\hline
\end{tabular}

Return on Questionnaire to Publishers. A questionnaire was sent to the editors of the six journals included in this study to obtain their book reviewing policies, par- are somewhat related to the field with which the book is concerned.

Only two of the journals give any definite instructions to the persons who write 
their book reviews. The Journal of Higher Education has a sample form letter, which is sent to prospective reviewers, giving directions as to the bibliographic entry and the number of words but saying nothing concerning the manner and treatment of the review itself.

The editors of the Journal of Educational Research ask their reviewers to be critical, and they definitely state that uncritical reviews are rejected. Doubtful reviews are read by one or more members of the editorial board before they are accepted.

Information about space limitation was checked on each questionnaire returned. The Junior College Journal limits reviews to one column, the Harvard Educational Review to approximately four hundred words, and the American Association of University Professors' Bulletin to two or three bulletin pages, which average one thousand words each, while the Journal of Educational Research states that only very broad limits are given to the length of review and the form letter of the Journal of Higher Education says that reviews are normally three or four hundred words in length, although one for a book of great importance may extend to five hundred words.

All the journals review books which are sent them by publishers but also write for important titles when not received otherwise.

The editors in each case select which books are to be reviewed. The American Association of University Professors' Bulletin chooses recent publications of interest to all college and university teachers. The Junior College Journal selects books just off the press, mostly in the education field, and includes some titles which they consider possible textbooks. The Journal of
Higher Education limits itself to outstanding books in the field of higher education, while the Journal of Educational Research is interested in research publications. They alone state that they choose books published within the current year of publication.

\section{Conclusions and Recommendations}

Conclusions. This study shows that reviews in the field of higher education furnish the librarian with sufficient bibliographic information and describe the contents of the books reviewed quite fully but leave much to be desired in evaluating the books for selection purposes. Of the books reviewed, only Io per cent were reviewed more than once.

Sixty-seven to 84 per cent of all signed reviews attempted to give an impartial estimate of the book by agreeing or disagreeing with the author's point of view. However, when it came to stating whether or not the book had the quality necessary to make it a permanent contribution, only Io to 29 per cent of the same reviewers committed themselves.

Another weak spot appeared in the field of comparison. The range here was from approximately 2 per cent for the Junior College Journal to 22 per cent for the Journal of Educational Research. In other words, the librarian seldom finds a review comparing a new book with other better-known titles.

The use of the score card for evaluating reviews in this study reveals the following :

I. On the whole the journals reviewed recent material.

2. Full authority of the reviewer is seldom given. In most instances only the name of the person and the institution with which he was connected were mentioned.

3. One of the weakest spots in the man- 
ner and treatment of reviews was in the lack of comparison with other titles.

4. The scope and form of the book reviewed were usually well-covered.

5. The reviews did not rate very high on the information they gave concerning the author of the book. Few reviewers mentioned the author at all; or, when they did, gave no information about him.

6. The reviews did not reveal to any great extent the originality or permanent value of the books.

7. Physical features, such as adequate index, documentation, appendices, bibliographies, and such, received little attention.

8. Trade information necessary for book selection purposes was adequately given.

9. Usually the longer the review the higher it rated on the score card, although the average rating for an individual review was only twenty-three out of a possible score of thirty-nine or forty-one. The length varied, with all but two of the journals averaging over five hundred words for a single review.

The score card provided a convenient way to check the characteristics of a review but did not show whether the reviewer presented a true picture of the book. That could be done only by examining the contents of the books themselves. Perhaps the chief value of such a score card is in its establishment of a practical analytical approach to a book review.

Perhaps the questionnaire to the editors of these journals showed up one of the greatest weaknesses in book reviewing in professional journals. Although instructions were given as to length and bibliographic form, it was assumed that other instructions as to how the review should be written, what points should be emphasized, the value of the book, and so forth, were unnecessary. Only one journal states that it instructed the reviewers to be critical.

Recommendations. A study of book reviews using some such score card as was developed for this essay might be made by comparing the information given in the review with that of the book itself, to see whether the review represented it fairly. Such a study might also make it possible to compose better questions to bring out the nature and value of a review. Some of the questions in the score card used in this study were improved by examining the reviews themselves.

The score card might then be used by several people examining the same reviews. Until that can be done there is no way of knowing the extent of objectivity of such a measurement.

It is also recommended that an outline or specifications, covering points in the score card, be used by the editorial boards of educational journals in giving instructions to their reviewers as a means of raising their book-reviewing standards. 